Supporting Information for

\title{
TRANSFORMATION OF THE ANTIBACTERIAL AGENT SULFAMETHOXAZOLE IN REACTIONS WITH CHLORINE: KINETICS, MECHANISMS, AND PATHWAYS
}

\author{
Michael Dodd ${ }^{\dagger}$ and Ching-Hua Huang* \\ School of Civil and Environmental Engineering, Georgia Institute of Technology \\ Atlanta, Georgia 30332 \\ *Corresponding author phone: 404-894-7694; fax: 404-894-8266; \\ e-mail: ching-hua.huang@ce.gatech.edu
}

Text S1. Procurement and sources of wastewater and drinking water samples.

Text S2. Quenching procedure for reactions of SMX and APMS with FAC.

Text S3. Fraction collection and LC/MS confirmation of products observed during kinetic monitoring studies.

Text S4. Sample purification and analysis of Product SMX 2 by ${ }^{1} \mathrm{H}$ NMR and GC/MS analyses.

Table S1. SMX/FAC reaction products detected in unquenched reaction solutions by LC/MS-ESI ${ }^{+}$

Figure S1. Effects of quenching procedures on HPLC-UV chromatograms $(\lambda=275 \mathrm{~nm})$ for SMX: (a) Unquenched SMX reaction solution (2:1 FAC:SMX) at 10 min.; (b) SMX reaction solution quenched with $\mathrm{Na}_{2} \mathrm{~S}_{2} \mathrm{O}_{3}$ at 10 min.; (c) $\mathrm{SMX}$ reaction solution quenched with $\mathrm{NH}_{4} \mathrm{Cl} / \mathrm{THAM} / \mathrm{CH}_{3} \mathrm{COOH}$ at 10 min. Reduction of isolated Product SMX2 yielded no identifiable products. Thus, reduction of the peak identified as N-chlorinated SMX appears to be responsible for most of the back-reaction depicted in these figures.

Figure S2. Stability of SMX/FAC solutions $\left([\mathrm{FAC}]_{0}:[\mathrm{SMX}]_{0}=2: 1, \mathrm{pH} 7\right)$ quenched after 10-minute reaction times with the "soft" quenching techniques described in Text S2. The X-axis represents time from sample quenching to sample analysis by HPLC. The y-axis represents measured SMX concentration in the quenched samples, normalized to the residual concentration of SMX measured (also after 10-minute reaction time) in a similar reaction sample that was not subject to quenching.

Figure S3. ${ }^{1} \mathrm{H}$ NMR spectra: (a) pure SMX, (b) Product SMX2.

\footnotetext{
†Present address: Swiss Federal Institute for Environmental Science and Technology (EAWAG); Ueberlandstrasse 133; CH-8600 Duebendorf, Switzerland
} 
Text S1. Procurement and sources of wastewater and drinking water samples

Secondary wastewater effluent was taken from an Atlanta regional wastewater reclamation facility (WRF) and filter box effluent was collected from a regional drinking water treatment plant (WTP). Unmodified samples were vacuum-filtered through $0.45 \mu \mathrm{m}$ pore-size membranes upon arrival in the laboratory, and stored on ice prior to use in experiments (no later than 2 days after collection). Water quality parameters were measured within 24 hours of sampling. The WRF sample was obtained from a point in that facility's treatment train just prior to application of chlorine gas (following typical secondary activated sludge treatment with nitrification/denitrification). The WTP sample was taken from filter box effluent situated at a point in that facility's treatment train subsequent to coagulation/flocculation/filtration and pre-oxidation with chlorine dioxide, and immediately prior to disinfection by chlorine gas. Calculations addressing the reaction of $\mathrm{HOCl} / \mathrm{OCl}^{-}$with chlorite, according to the rate-limiting step shown in equation (S1) (1)

$\mathrm{ClO}_{2}^{-}+\mathrm{HOCl}+\mathrm{H}+\stackrel{k_{1}}{\longrightarrow} \mathrm{Cl}_{2} \mathrm{O}_{2}+\mathrm{H}_{2} \mathrm{O}$

(where $\mathrm{k}_{1}=1.1 \times 10^{6} \mathrm{M}^{-2} \mathrm{~s}^{-1}(2)$ ) indicate that such reactions would not have influenced experimental observations, and would not have led to production of significant concentrations of $\mathrm{ClO}_{2}$ during relevant reaction monitoring periods. Thus, the presence of chlorite should not have affected experimental observations. Residual chlorine measurements verified the absence of available chlorine (free or combined) in each sample. Important water quality parameters are given in Table 2 (main text). pH, DOC, and $\mathrm{NH}_{3}-\mathrm{N}$ were measured in the laboratory. Dissolved organic carbon (DOC) analyses were conducted using a Shimadzu TOC-5050a analyzer and performed according to standard methods for determination of non-purgeable organic carbon (3). $\mathrm{NH}_{3}-\mathrm{N}$ measurements were conducted titrimetrically, according to standard methods (3). Alkalinity measurements were provided by plant personnel at the facilities from which each sample was obtained.

Text S2. Quenching procedure for reactions of SMX and APMS with FAC. 
Experiments showed that sodium thiosulfate $\left(\mathrm{Na}_{2} \mathrm{~S}_{2} \mathrm{O}_{3}\right)$ reduces a N-chlorinated intermediate of SMX back to the parent compound (Figure S1), and is thus an unsuitable quenching agent for monitoring reactions of SMX with free chlorine. In response, a novel "soft" quenching technique - using $\mathrm{NH}_{4} \mathrm{Cl}$ as a reductant - was developed to allow evaluation of reaction kinetics of SMX with FAC.

The applicability of $\mathrm{NH}_{4} \mathrm{Cl}$ as a quenching agent is based upon experimental results that show: (i) $\mathrm{NH}_{4}{ }^{+} / \mathrm{NH}_{3}$ can effectively out-compete $\mathrm{SMX}$ for free chlorine at $\mathrm{pH} \sim 8.3$ (data not shown), (ii) reactions between combined chlorine and SMX are extremely slow $\left(\mathrm{t}_{1 / 2}>1 \mathrm{~d}\right.$ ) at $\mathrm{pH}<5$ (Figure 3 in main text), and (iii) stability of the N-chlorinated SMX intermediate in the presence of free $\mathrm{NH}_{4}{ }^{+} / \mathrm{NH}_{3}$ is satisfactory at acidic $\mathrm{pH}$ during a suitable analytical period (Figure $\mathrm{S} 2$ ).

2.5-mL, amber, borosilicate glass autosampler vials were amended with tris(hydroxymethyl) aminomethane (THAM) and $\mathrm{NH}_{4} \mathrm{Cl}$ prior to sampling. The amount of $\mathrm{NH}_{4} \mathrm{Cl}$ added was in molar excess of maximum expected free chlorine residual (i.e., initial FAC concentration). Appropriate amounts of THAM were added to ensure that $\mathrm{pH}$ of 1 - $\mathrm{mL}$ samples added to these vials would be $\sim 8.3$ at the time of quenching. 1-mL samples of SMX/FAC reaction solutions were added to the $\mathrm{NH}_{4} \mathrm{Cl} / \mathrm{THAM}$ solutions at appropriate time intervals during reaction monitoring periods. $\mathrm{CH}_{3} \mathrm{COOH}$ was added to each sample to adjust $\mathrm{pH}$ to between 4.5 and 5 immediately after sampling. The latter step was performed to retard chlorine transfer reactions between the N-chlorinated SMX intermediate and $\mathrm{NH}_{4}{ }^{+} / \mathrm{NH}_{3}$ by protonating $\mathrm{NH}_{3}$. Acidification of samples to $\mathrm{pH}<4.5$ was observed to result in further oxidation of SMX (presumably from formation of stronger oxidizing species such as $\mathrm{NCl}_{3}(4)$ or $\mathrm{NH}_{3} \mathrm{Cl}^{+}(5)$ ) - leading to additional substrate decay prior to analysis. THAM and $\mathrm{CH}_{3} \mathrm{COOH}$ dosages were selected by determining the respective quantities necessary to sequentially adjust $20-\mathrm{mL}$ of the $0.01 \mathrm{M}$ buffer solutions used in each kinetic experiment to desired $\mathrm{pH}$ values (first 8.3, then $<5$ ). Doses of THAM and $\mathrm{CH}_{3} \mathrm{COOH}$ stock solutions $(0.1$ or $1 \mathrm{M}$, depending on the starting $\mathrm{pH}$ of each reaction solution buffer tested) required for these $\mathrm{pH}$ adjustments were then scaled down to $1-\mathrm{mL}$ sample volumes. 
Samples quenched by this technique could be preserved for approximately one hour with less than $10 \%$ deviation of sample character from that of the initial sampling time (Figure S2). Expedient sample analysis (total analytical time for a set of five samples was approximately 1.5 hours), permitted monitoring of otherwise unstable reaction systems with considerably greater accuracy than would be achievable using stronger reductants. The $\mathrm{NH}_{4} \mathrm{Cl}$ technique was assumed to be equally applicable to reactions involving APMS, on the basis of the structural similarities between SMX and APMS.

Text S3. Fraction collection and LC/MS confirmation of products observed during kinetic monitoring studies.

$500 \mu \mathrm{L}$ volumes of unquenched SMX reaction solutions (at initial substrate concentration of 100 $\mathrm{mg} / \mathrm{L}$, and 4:1 [FAC $]_{0}:[\mathrm{substrate}]_{0}$ ratio) were separated by HPLC on the same Zorbax RX-C18 column described in the main text, under analytical conditions similar to those used in kinetic experiments (discussed in the main text). Fractions corresponding to major product peaks (observed via UV) were subsequently isolated using post-column fraction collection. These diluted fractions were then reconcentrated to $\sim 500 \mu \mathrm{L}$ by evaporation under nitrogen gas and reconstitution in methanol, and analyzed by LC/MS (methods described in the main text) to obtain the masses of products contained within them. Retention times of the peaks contained within these fractions - as observed on the Zorbax RX-C18 column - were compared to retention times of peaks observed in kinetic experiments, in turn facilitating assignment of structures to transformation product peaks observed during the kinetic experiments.

Text S4. Sample purification and analysis of Product SMX2 by ${ }^{1} \mathrm{H}$ NMR and GC/MS analyses $100 \mathrm{~mL}$ of an unbuffered $200 \mathrm{mg} / \mathrm{L}$ SMX solution was dosed with $168 \mathrm{mg} / \mathrm{L}$ FAC (a 3:1 $[\mathrm{FAC}]_{0}:[\mathrm{substrate}]_{0}$ molar ratio) and allowed to react for 10 minutes. The unquenched reaction solution was passed through a 5-mL Waters Oasis HLB cartridge - first conditioned with 2-mL of methanol and 2$\mathrm{mL}$ of water - at $\sim 1 \mathrm{~mL} / \mathrm{min}$ under vacuum. The contents of the cartridge were then eluted with $5 \mathrm{~mL}$ 
each of $75 \%$ methanol solution, $90 \%$ methanol solution, and pure methanol in sequence. $75 \%$ methanol was sufficient to remove impurities from the sample while allowing retention of Product SMX2.

Product SMX2 was eluted in the fraction corresponding to $90 \%$ methanol. $100 \mu \mathrm{L}$ of the $90 \%$ $\mathrm{MeOH}$ fraction was analyzed by HPLC at 205 and $275 \mathrm{~nm}$ to verify the absence of significant peaks resulting either from additional reaction products or from residual SMX. The remainder of this fraction was evaporated at room temperature under a gentle stream of $\mathrm{N}_{2}$ gas until only an amorphous brown precipitate remained. This precipitate was either: 1) dissolved in $0.5 \mathrm{~mL}$ of $\mathrm{d}_{6}$-acetone and transferred to a 5-mm NMR tube for analysis with a Bruker AMX $400 \mathrm{NMR}$ instrument operating at $400 \mathrm{mHz}$ and $27^{\circ} \mathrm{C}$; or 2) dissolved in 1-mL of $\mathrm{MeCl}_{2}$ for analysis with an Agilent 6890/5973 GC/MS system equipped with a HP-5MS 5\% phenyl methyl siloxane capillary column $(30 \mathrm{~m} \times 250 \mu \mathrm{m} \times 0.25 \mu \mathrm{m})$, using electron ionization at $70 \mathrm{eV}$, over a mass scan range of $35-550 \mathrm{~m} / \mathrm{z}$. GC method settings were as follows: splitless injection with helium as the carrier gas at $1 \mathrm{~mL} / \mathrm{min}$, and inlet temperature of $250^{\circ} \mathrm{C}$; temperature gradient starting at $70^{\circ} \mathrm{C}$ and ramped to $280^{\circ} \mathrm{C}$ at $10^{\circ} / \mathrm{min}$, then held at $280^{\circ} \mathrm{C}$ for 10 minutes. MS ion source and quadrupole temperatures were $230^{\circ} \mathrm{C}$ and $150^{\circ} \mathrm{C}$, respectively. 
Table S1. SMX/FAC reaction products detected in unquenched reaction solutions by LC/MS-ESI ${ }^{+}$

\begin{tabular}{|c|c|c|c|}
\hline RT (min) & $\mathbf{M}+\mathbf{H}^{+}$ & Compound & $\mathbf{m} / \mathbf{z}$ \\
\hline 7.704 & 99 & AMI & 99, $72(18 \%)$ \\
\hline 8.604 & 190 & & $190,148(5 \%), 147(5 \%)$ \\
\hline 12.418 & 254 & $\mathrm{SMX}^{c}$ & 254, $156(89 \%), 108(71 \%), 92(77 \%)$ \\
\hline $14.17^{a}$ & $141^{b}$ & Product SMX2 & $141(143), 113(115), 87(88), 80,78,51(53), 52(54)$ \\
\hline 15.833 & 288 & Product SMX1 & $288(290)$ \\
\hline 16.713 & 288 & N-chlorinated SMX ${ }^{c}$ & $\begin{array}{l}288(290), 253(45 \%), 190(84 \%, 192), 142(15 \%, 144), \\
126(5 \%, 129)\end{array}$ \\
\hline 20.279 & 501 & Dimer & 501, $437(62 \%), 410(96 \%)$ \\
\hline 21.193 & 503 & Dimer & 503, $439(6 \%), 412(7 \%)$ \\
\hline 23.378 & 377 & & 377 (379) \\
\hline
\end{tabular}

- HPLC gradient elution with $0.2 \%$ Formic acid and acetonitrile: $20 \% \mathrm{MeCN}$ at 0 min, increased to $60 \% \mathrm{MeCN}$ at $20 \mathrm{~min}$, increased to $95 \% \mathrm{MeCN}$ at $25 \mathrm{~min}$, followed by a 5 -min wash of $95 \%$ $\mathrm{MeCN}$.

- Base peaks are shown in bold, with fragment ion peaks in plain text. Relative fragment peak abundances are given as percentage of base peak height. $\mathrm{Cl}$ isotope peak masses are also indicated in parentheses.

- ${ }^{a}$ The retention time provided is for UV detection during LC/MS analysis, at $275 \mathrm{~nm} .{ }^{b}$ Product SMX2 yielded no mass spectrum in LC/MS, but could be detected by GC/MS analysis (see Text S4, Figure $4 \mathrm{c}$ in main text). ${ }^{c} \mathrm{LC} / \mathrm{MS}$ spectrum obtained at $120 \mathrm{eV}$ fragmentation voltage 

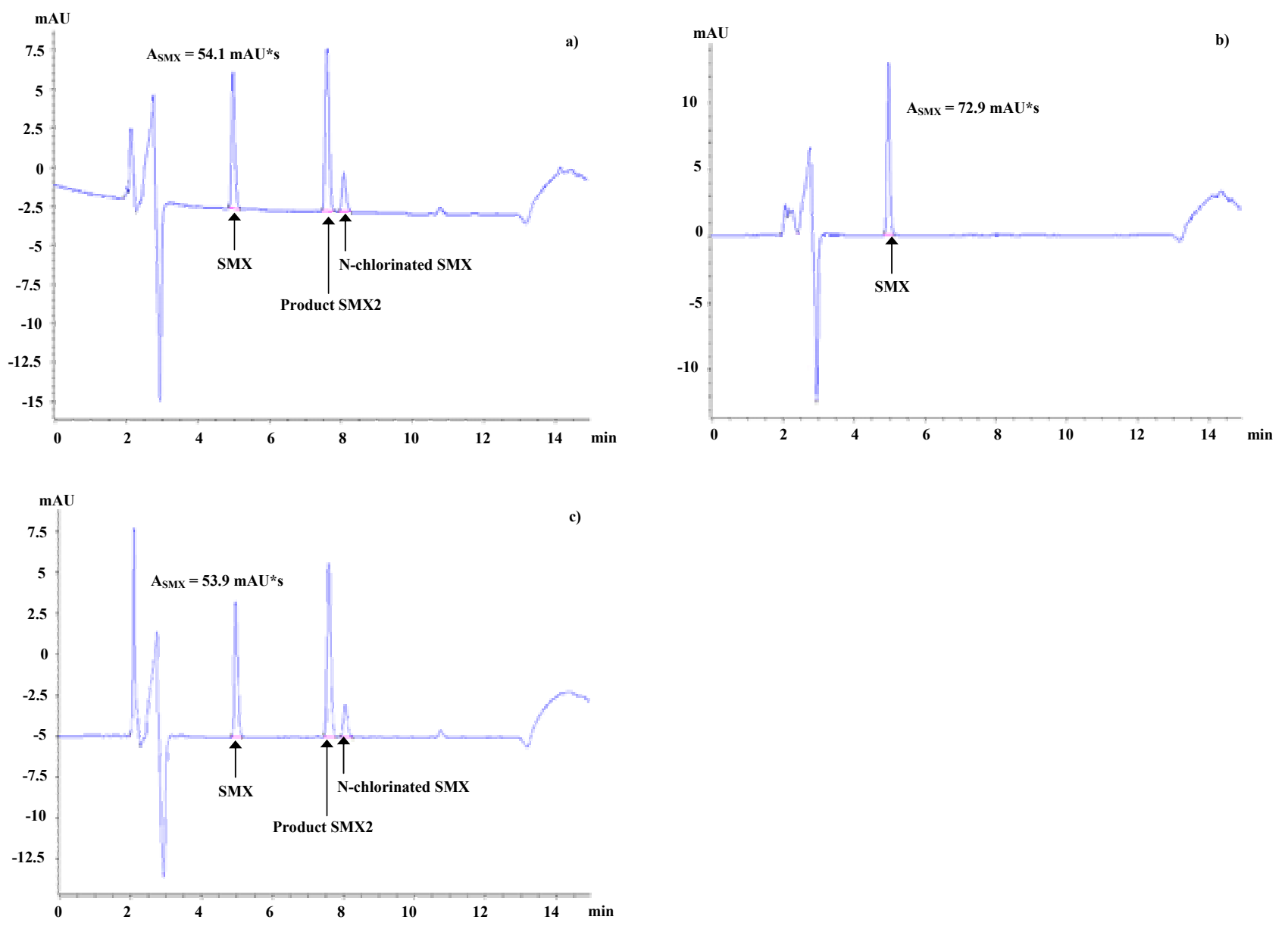

Figure S1. Effects of quenching procedures on HPLC-UV chromatograms $(\lambda=275 \mathrm{~nm})$ for SMX: (a) Unquenched SMX reaction solution (2:1 FAC:SMX) at 10 min.; (b) SMX reaction solution quenched with $\mathrm{Na}_{2} \mathrm{~S}_{2} \mathrm{O}_{3}$ at 10 min.; (c) $\mathrm{SMX}$ reaction solution quenched with $\mathrm{NH}_{4} \mathrm{Cl} / \mathrm{THAM} / \mathrm{CH}_{3} \mathrm{COOH}$ at 10 min. Reduction of isolated Product SMX2 yielded no identifiable products. Thus, reduction of the peak identified as N-chlorinated SMX appears to be responsible for most of the back-reaction depicted in these figures. 


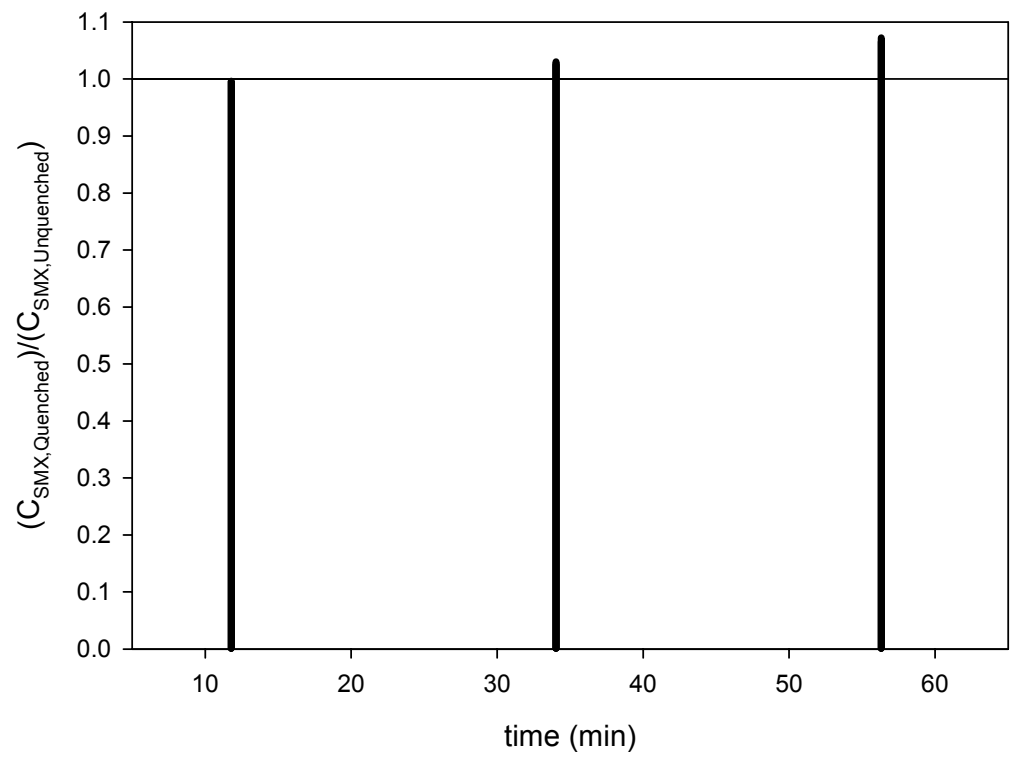

Figure S2. Stability of SMX/FAC solutions $\left([\mathrm{FAC}]_{0}:[\mathrm{SMX}]_{0}=2: 1, \mathrm{pH} 7\right)$ quenched after 10-minute reaction times with the "soft" quenching techniques described in Text S2. The X-axis represents time from sample quenching to sample analysis by HPLC. The y-axis represents measured SMX concentration in the quenched samples, normalized to the residual concentration of SMX measured (also after 10-minute reaction time) in a similar reaction sample that was not subject to quenching. 

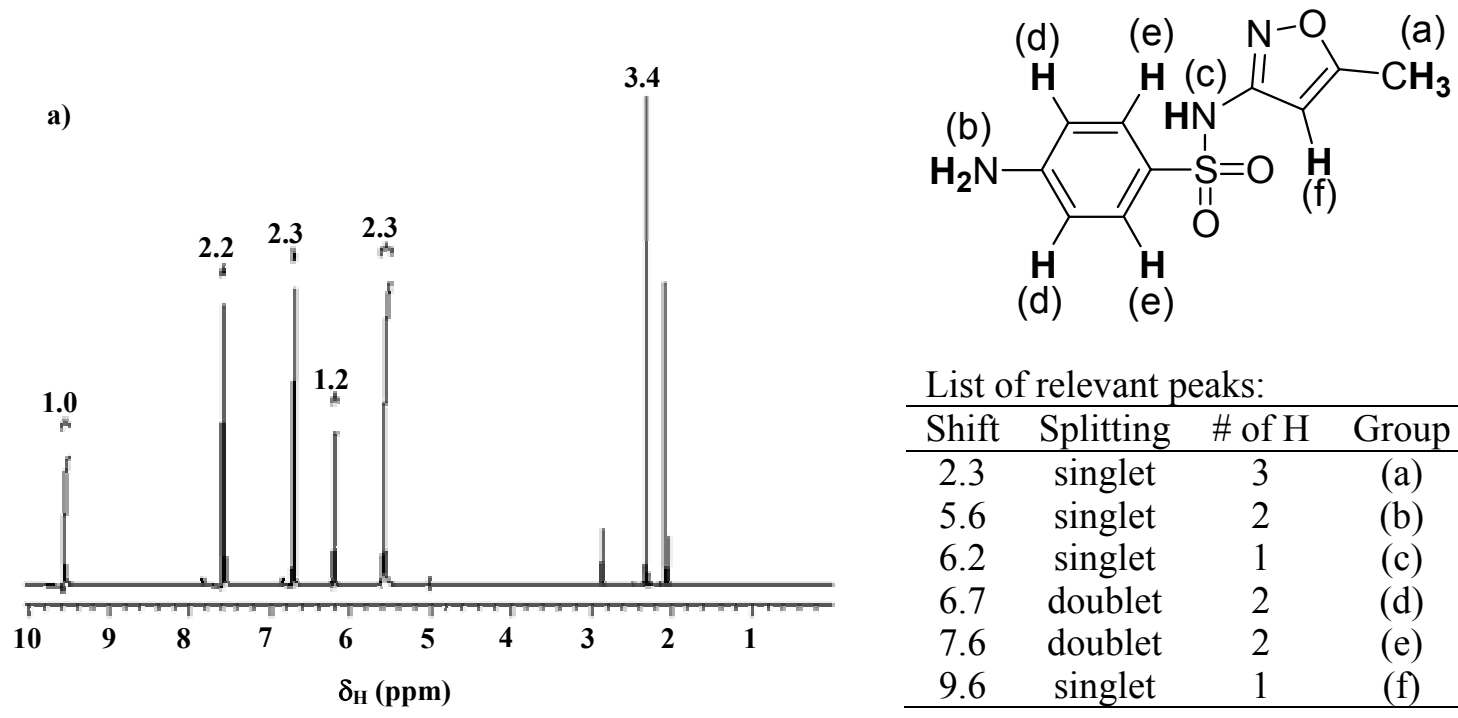

List of relevant peaks:

\begin{tabular}{cccc}
\hline Shift & Splitting & \# of H & Group \\
\hline 2.3 & singlet & 3 & (a) \\
5.6 & singlet & 2 & (b) \\
6.2 & singlet & 1 & (c) \\
6.7 & doublet & 2 & (d) \\
7.6 & doublet & 2 & (e) \\
9.6 & singlet & 1 & (f) \\
\hline
\end{tabular}

b)

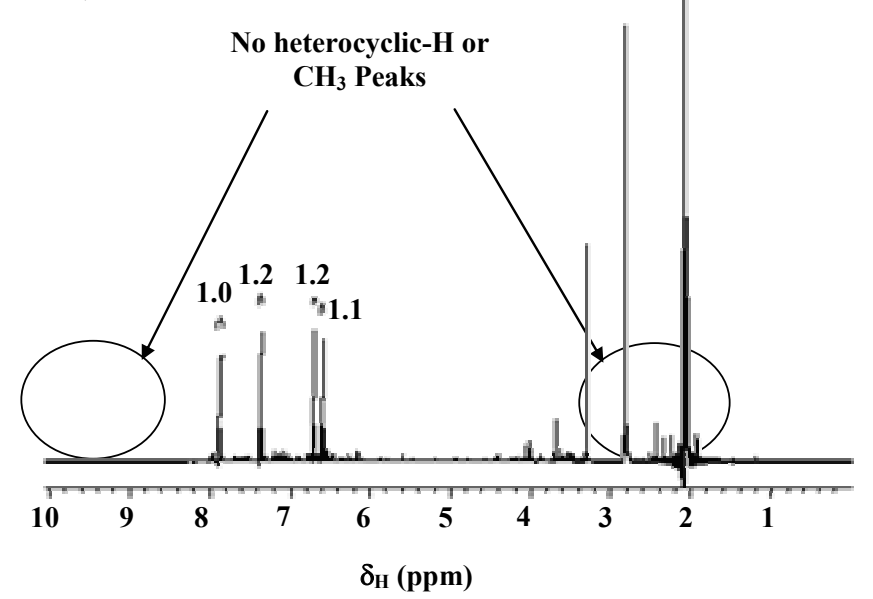

List of relevant peaks:

\begin{tabular}{ccc}
\hline Shift & Splitting & \# of H \\
\hline 6.6 & doublet & 1 \\
6.7 & doublet & 1 \\
7.4 & doublet & 1 \\
7.9 & doublet & 1 \\
\hline
\end{tabular}

Figure S3. ${ }^{1} \mathrm{H}$ NMR spectra: (a) pure SMX, (b) Product SMX2. 


\section{Literature Cited}

1. Jia, Z.; Margerum, D. W.; Francisco, J. S. Inorg. Chem. 2000, 39, 2614-2620.

2. $\quad$ Peintler, G.; Nagypal, I.; Epstein, I. R. J. Phys. Chem. 1990, 94, 2954-2958.

3. Standard Methods for the Examination of Water and Wastewater; 20 ed.; APHA, AWWA, WPCF: Washington, 1998.

4. White, G. C. Handbook of Chlorination and Alternative Disinfectants; John Wiley \& Sons, Inc.: New York, NY, 1999.

5. Snyder, M. P.; Margerum, D. W. Inorg. Chem. 1982, 21, 2545-2550. 